\title{
Genetic association of catechol-O-methyltransferase val(158)met polymorphism in Saudi schizophrenia patients
}

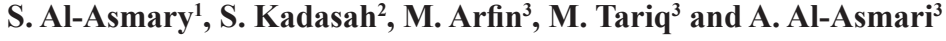 \\ ${ }^{1}$ Department of Neuropsychiatry, Riyadh Military Hospital, Riyadh, Saudi Arabia \\ ${ }^{2}$ Department of Psychiatry, Riyadh Military Hospital, Riyadh, Saudi Arabia \\ ${ }^{3}$ Research Center, Riyadh Military Hospital, Riyadh, Saudi Arabia \\ Corresponding author: A. Al-Asmari \\ E-mail: abdulrahman.alasmari@gmail.com
}

Genet. Mol. Res. 13 (2): 3079-3088 (2014)

Received February 5, 2013

Accepted October 23, 2013

Published April 17, 2014

DOI http://dx.doi.org/10.4238/2014.April.17.4

\begin{abstract}
Schizophrenia is a complex neuropsychiatric disorder strongly associated with dopamine dysregulation. Catechol-O-methyltransferase (COMT) is a candidate gene for schizophrenia that encodes an enzyme involved in the metabolic inactivation of dopamine. The COMT Val ${ }^{158}$ Met polymorphism has been associated with schizophrenia and has significant inter- and intra-ethnic variations. We examined a possible association between the COMT Val ${ }^{158}$ Met polymorphism and schizophrenia in Saudis, taking into account gender and functional symptoms. Saudi subjects including 172 unrelated schizophrenia patients and 177 matched controls were analyzed for allele and genotype distribution of the COMT Val ${ }^{158}$ Met polymorphism. We found significant differences in allele and genotype frequencies between patients and controls. The frequencies of $\mathrm{Met}^{158}$ allele (A) and genotype Val ${ }^{158}$ Met (GA) were significantly higher in patients compared to those in controls. On the other hand, the frequencies of Val ${ }^{158}$ allele $(G)$ and genotype $\mathrm{Val}^{158} \mathrm{Val}(\mathrm{GG})$ were significantly higher in controls than those in patients. We found a significant association of the COMT Val ${ }^{158} \mathrm{Met}$
\end{abstract}


polymorphism with schizophrenia. Moreover, male patients with the COMT Val ${ }^{158}$ Met polymorphism had increased risk for schizophrenia compared to female subjects. However, no association was noticed with the COMT Val ${ }^{158}$ Met polymorphism and negative or positive symptoms of schizophrenia. These results provide evidence for a role of the COMT Val ${ }^{158}$ Met polymorphism in the etiopathophysiology of schizophrenia in Saudi population. It appears that the association of the COMT Val ${ }^{158} \mathrm{Met}$ polymorphism with schizophrenia is mediated by gender.

Key words: Schizophrenia; Catechol-O-methyltransferase (COMT); Polymorphism

\section{INTRODUCTION}

Schizophrenia is one of the most disabling psychiatric disorders, which according to the World Health Organization affects around 24 million people worldwide, with a prevalence ranging from 0.7 to $1.1 \%$. Schizophrenia affects men and women equally, but its onset in women is typically 5 years later than in men. On the other hand, schizophrenia has long been regarded as a heterogeneous entity, and over the decades researchers have sought consistent subpatterns that could explain different aspects of this complex disorder. Andreasen and Olsen (1982) have proposed that two distinct syndromes in schizophrenia can be discerned from the phenomenal profiles. Type I, or positive syndrome is composed of florid symptoms such as delusions, hallucinations and disorganized thinking, which are superimposed on the mental status. Type II, or negative syndrome is characterized by deficits in cognitive, affective and social functions, including blunting of affect and passive withdrawal (Kay et al., 1987). It has been speculated that these syndromes in schizophrenia bear etiological, pharmacological and prognostic import. Due to its early age of onset and the lifelong disability generally accompanied by emotional and financial devastation, schizophrenia brings to its victims and their families, it is one of the most catastrophic mental illnesses. Available data suggest that the etiology of schizophrenia involves the interplay of complex polygenic influences and environmental risk factors operating on brain maturational processes. Numerous studies have shown that schizophrenia is a multifactorial disease involving several genes, with each susceptibility gene having only a modest individual effect (Harrison and Weinberger, 2005).

Dopamine dysregulation has long been believed to be associated with schizophrenia pathogenesis (Howes et al., 2009). Catechol-O-methyltransferase (COMT) [MIM 116790] is a catabolic enzyme involved in the degradation of a number of bioactive molecules including dopamine. The enzyme is encoded by the COMT gene. COMT is located (along with 47 other genes) in a fragment of chromosome 22q11 that when deleted results in a complex syndrome, the psychiatric manifestations of which include schizophrenia and other psychoses (Murphy, 2002). These observations have placed COMT near the top of a rather long list of plausible candidate genes for schizophrenia. The ability to test the hypothesis that COMT may be a susceptibility gene for schizophrenia has been simplified in principle by the existence of a valine-to-methionine (Val ${ }^{158} \mathrm{Met}$ ) polymorphism (rs4680), which results respectively in highand low-activity forms of the enzyme (Lotta et al., 1995). Given the unequivocal effect of this polymorphism on the function of COMT, and the evidence for a critical role for dopamine in the pathophysiology and treatment of psychosis, there are strong prior expectations that 
Val ${ }^{158}$ Met influences susceptibility to schizophrenia as well as other psychiatric phenotypes. Indeed, the $\mathrm{Va}^{158}{ }^{158}$ Met polymorphism has become the most widely studied polymorphism for various psychiatric diseases including schizophrenia. Several investigators have reported a significant association between the COMT polymorphism and schizophrenia (Sazci et al., 2004; Lafuente et al., 2008; Gupta et al., 2009; Hoenicka et al., 2010; Costas et al., 2011; Wan et al., 2011), while other studies have shown a lack of association between the COMT (Val ${ }^{158} \mathrm{Met}$ ) polymorphism and schizophrenia (Karayiorgou et al., 1998; Okochi et al., 2009; Kong et al., 2011; Zhang et al., 2012). Moreover, the results of the studies on Caucasian and Asian ethnic groups have shown both inter- and intra-ethnic variations (Rosa et al., 2004; Gupta et al., 2009; Nieratschker et al., 2010; Wang et al., 2010). Since the findings of previous studies on the role of COMT (Val ${ }^{158} \mathrm{Met}$ ) polymorphism in schizophrenia remain inconclusive, this study was undertaken to determine the association between the COMT (Val ${ }^{158} \mathrm{Met}$ ) polymorphism and schizophrenia with emphasis on the role of gender and functional symptoms in Saudi patients.

\section{MATERIAL AND METHODS}

\section{Subjects}

The study population consisted of a total of 349 Saudi subjects of either gender. The sample included 172 schizophrenia patients recruited from the outpatient psychiatric clinic of Riyadh Military Hospital (RMH), Riyadh, Saudi Arabia, and 177 age- and gender-matched healthy volunteers. All subjects were biologically unrelated Saudis. Among 172 confirmed cases of schizophrenia, 91 patients were with negative symptoms while 81 with positive symptoms. There were 49 females and 123 males with a mean age of $39 \pm 12.5$ years and mean disease duration of $9 \pm 4.5$ years, while age of onset of disease varied from 19 to 64 years. The female to male ratio of schizophrenia patients in our study was 1:2.5. The control group consisted of 50 females and 127 males with mean age of $35 \pm 10.5$ years.

The diagnosis of schizophrenia was based on the criteria mentioned in the American Psychiatric Association Diagnostic and Statistical Manual of Mental Disorders, DSM-IV-TR Version. These criteria use the self-reported experience of the patient and reported abnormalities in behavior and a comprehensive clinical assessment by a neuropsychiatrist. If diagnosis of schizophrenia was confirmed by the above-mentioned criteria, patients were further assessed for positive and negative symptoms using Positive or Negative Syndrome Scale (PANSS) involving further clinical interview, cognitive testing, motor assessment, and careful review of medical and historical records as described by Kay et al. (1987). All subjects in the control group were screened using a questionnaire about the health status and excluded if they had any history of neurological, psychiatric or medical disorders or had a past or present involvement in substance abuse. None of the control subjects had a first- or second-degree relative with any mental illness. A number of baseline parameters to rule out any psychotic illness were adopted as described by Johnstone et al. (2005). Written informed consent was obtained from all subjects in accordance with ethical guidelines set by a local Ethics Committee.

\section{Polymerase chain reaction (PCR) amplification}

Genomic DNA was extracted from the blood of schizophrenia patients and controls using 
the QIAamp ${ }^{\mathrm{R}}$ DNA mini kit (Qiagen, USA). A genomic DNA fragment containing the Val ${ }^{158} \mathrm{Met}$ polymorphism in the human COMT sequence (GenBank Accession No. AY 341246 with the SNP site being in the nucleotide 23,753 of this accession number) was amplified by PCR (Ruiz-Sanz et al., 2007). PCR amplification was carried out using Ready-to-Go PCR Beads (Amersham Biosciences, USA) in a Gradient Master Thermal Cycler (Eppendorf, Germany) with an initial denaturation at $94^{\circ} \mathrm{C}$ for $4 \mathrm{~min}$ followed by 30 cycles of $94^{\circ} \mathrm{C}$ for $30 \mathrm{~s}, 62^{\circ} \mathrm{C}$ for $30 \mathrm{~s}$ and $72^{\circ} \mathrm{C}$ for $20 \mathrm{~s}$ and a final extension at $72^{\circ} \mathrm{C}$ for $5 \mathrm{~min}$. PCR products obtained were separated by electrophoresis on a $1.5 \%$ agarose gel in TAE buffer, visualized by ethidium bromide fluorescence. This procedure rendered 3 bands in heterozygotes $\left(626,451\right.$ and $222 \mathrm{bp}$ ) and 2 bands in homozygotes (Met ${ }^{158}$ Met resulting in 626 and $222 \mathrm{bp}$, and Val ${ }^{158}$ Val resulting in 626 and $451 \mathrm{bp}$ ).

\section{Statistical analysis}

The differences in genotype and allele frequencies between patients and controls were analyzed with the Fisher exact test using the CalcFisher software (http://www.jstatsoft.org/ v08/i21/paper).

$\mathrm{P} \leq 0.05$ was considered to be significant. The strength of the association of disease with respect to a particular genotype/allele are reported with the odds ratio interpreted as relative risk (RR) following the method of Woolf as described by Schallreuter et al. (1993). RR indicates how many times more frequent a disease is in the positive subjects compared with allele/genotype-negative subjects. It is calculated for a genotype/allele that is increased or decreased in schizophrenia patients compared to the frequency in normal Saudi subjects. RR was calculated for all the subjects using the following formula:
$\mathrm{RR}=(\mathrm{a}) \mathrm{x}(\mathrm{d}) /(\mathrm{b}) \mathrm{x}(\mathrm{c})$
(a) $=$ number of patients expressing the allele or genotype
(b) = number of patients without allele or genotype expression
(c) = number of controls expressing the allele or genotype
(d) = number of controls without allele or genotype expression

The etiologic fraction (EF) indicates the hypothetical genetic component of the disease. EF values of $>0.00-0.99$ are significant. It is calculated for positive associations (RR $>$ 1) using the following formula:

$\mathrm{EF}=(\mathrm{RR}-1) \mathrm{f} / \mathrm{RR}$, where $\mathrm{f}=\mathrm{a} / \mathrm{a}+\mathrm{c}$.

Preventive fraction (PF) indicates the hypothetical protective effect of one allele/ genotype for a disease. It is calculated for negative associations $(\mathrm{RR}<1)$ using the following formula. Values of $<1.0$ indicate the protective effect of an allele/genotype against the manifestation of disease.

$$
P F=(1-R R) f / R R(1-f)+f, \text { where } f=a / a+c .
$$

\section{RESULTS}

The frequencies of genotypes and alleles of the $V a{ }^{158} \mathrm{Met}$ polymorphism were obtained from schizophrenia patients and matched controls (Tables 1-5). In the patient group, there were 12 (6.98\%) Val ${ }^{158}$ homozygotes, 111 (64.53\%) Val ${ }^{158}$ Met heterozygotes, and 49 
(28.49\%) Met ${ }^{158}$ homozygotes. The control group contained $54(30.50 \%)$ Val ${ }^{158}$ homozygotes, $71(40.11 \%) \mathrm{Val}^{158} \mathrm{Met}$ heterozygotes, and $52(29.38 \%) \mathrm{Met}^{158}$ homozygotes. The frequencies of genotype $\mathrm{Val}^{158} \mathrm{Val}$ as well as $\mathrm{Val}^{158} \mathrm{Met}$ differed significantly in patient and control groups $(\mathrm{P}=0.0001)$. The genotype $\mathrm{Va}{ }^{158} \mathrm{Val}$ was predominant in controls, whereas the genotype $\mathrm{Va}^{158} \mathrm{Met}$ was found to be increased in the patient group. Allele A (Met)-containing genotypes $(\mathrm{GA}+\mathrm{AA})$ were found in $93.02 \%$ of the patients and $69.49 \%$ of controls $(\mathrm{P}=0.0001)$. The frequencies of both alleles also differed significantly in patients and the control group $(\mathrm{P}=$ $0.0029)$ and allele Met ${ }^{158}$ was found to be associated with schizophrenia $(\mathrm{RR}=1.583, \mathrm{EF}=$ 0.200). The genotype Val/Met was significantly associated with schizophrenia ( $P=0.0001$, $\mathrm{RR}=2.716, \mathrm{EF}=0.385)$. On stratification of the patients with negative or positive symptoms of schizophrenia and comparing with controls, a similar distribution pattern of alleles and genotypes was noticed in the two groups (Tables 2 and 3).

Table 1. Genotype and allele frequencies of the COMT (Val $\left.{ }^{158} \mathrm{Met}\right)$ polymorphism in schizophrenia patients and matched controls.

\begin{tabular}{|c|c|c|c|c|c|c|c|}
\hline \multirow[t]{2}{*}{ Genotype/ Allele } & \multicolumn{2}{|c|}{ Schizophrenia $(\mathrm{N}=172)$} & \multicolumn{2}{|c|}{ Control $(\mathrm{N}=177)$} & \multirow[t]{2}{*}{$\mathrm{P}$} & \multirow[t]{2}{*}{ RR } & \multirow[t]{2}{*}{$\mathrm{EF}^{\dagger} / \mathrm{PF}$} \\
\hline & $\mathrm{N}$ & $\%$ & $\mathrm{~N}$ & $\%$ & & & \\
\hline GG (val/val) & 12 & 6.976 & 54 & 30.508 & $0.0001 *$ & 0.170 & 0.469 \\
\hline GA (val/met) & 111 & 64.534 & 71 & 40.112 & $0.0001^{*}$ & 2.716 & $0.385^{\dagger}$ \\
\hline AA (met/met) & 49 & 28.488 & 52 & 29.378 & 0.9062 & 0.957 & 0.021 \\
\hline $\mathrm{GA}+\mathrm{AA}$ & 160 & 93.023 & 123 & 69.491 & $0.0001 *$ & 5.853 & $0.468^{\dagger}$ \\
\hline G-allele (val) & 135 & 39.244 & 179 & 50.564 & $0.0029 *$ & 0.631 & 0.201 \\
\hline A-allele (met) & 209 & 60.755 & 175 & 49.435 & $0.0029 *$ & 1.583 & $0.200^{\dagger}$ \\
\hline
\end{tabular}

$\mathrm{N}=$ number of subjects; $\mathrm{RR}=$ relative risk; $\mathrm{EF}=$ etiological fraction; $\mathrm{PF}=$ preventive fraction. *Statistically significant.

\begin{tabular}{|c|c|c|c|c|c|}
\hline \multirow[t]{2}{*}{ Genotype } & \multicolumn{2}{|c|}{ With negative symptoms $(\mathrm{N}=91)$} & \multicolumn{2}{|c|}{ Control $(\mathrm{N}=177)$} & \multirow[t]{2}{*}{$\mathrm{P}$} \\
\hline & $\mathrm{N}$ & $\%$ & $\mathrm{~N}$ & $\%$ & \\
\hline GG (val/val) & 7 & 7.692 & 54 & 30.508 & $0.0001 *$ \\
\hline GA (val/met) & 57 & 62.637 & 71 & 40.112 & $0.0005^{*}$ \\
\hline $\mathrm{AA}$ (met/met) & 27 & 29.670 & 52 & 29.378 & 0.999 \\
\hline G-allele (val) & 71 & 39.01 & 179 & 50.564 & $0.013^{*}$ \\
\hline A-allele (met) & 111 & 60.99 & 175 & 49.435 & $0.013 *$ \\
\hline
\end{tabular}

$\mathrm{N}=$ number of subjects. $*$ Statistically significant.

\begin{tabular}{|c|c|c|c|c|c|}
\hline \multirow[t]{2}{*}{ Genotype } & \multicolumn{2}{|c|}{ With positive symptoms $(\mathrm{N}=81)$} & \multicolumn{2}{|c|}{ Control $(\mathrm{N}=177)$} & \multirow[t]{2}{*}{$P$} \\
\hline & $\mathrm{N}$ & $\%$ & $\mathrm{~N}$ & $\%$ & \\
\hline GG (val/val) & 5 & 6.173 & 54 & 30.508 & $0.0001 *$ \\
\hline GA (val/met) & 53 & 65.432 & 71 & 40.112 & $0.0001 *$ \\
\hline AA (met/met) & 23 & 28.395 & 52 & 29.378 & 0.9999 \\
\hline G-allele (val) & 63 & 38.89 & 179 & 50.564 & $0.0173 *$ \\
\hline A-allele (met) & 99 & 61.11 & 175 & 49.435 & $0.0173 *$ \\
\hline
\end{tabular}

$\mathrm{N}=$ number of subjects. $*$ Statistically significant. 
Table 4. Genotype and allele frequencies of the COMT (Val $\left.{ }^{158} \mathrm{Met}\right)$ polymorphism in male schizophrenia patients and male controls.

\begin{tabular}{|c|c|c|c|c|c|c|c|}
\hline \multirow[t]{2}{*}{ Genotype/ allele } & \multicolumn{2}{|c|}{ Patients $(\mathrm{N}=123)$} & \multicolumn{2}{|c|}{ Controls $(\mathrm{N}=127)$} & \multirow[t]{2}{*}{$\mathrm{P}$} & \multirow[t]{2}{*}{$\mathrm{RR}$} & \multirow[t]{2}{*}{$\mathrm{EF}^{\dagger} / \mathrm{PF}$} \\
\hline & $\mathrm{N}$ & $\%$ & $\mathrm{~N}$ & $\%$ & & & \\
\hline GG (val/val) & 8 & 6.504 & 50 & 39.4 & $0.0001^{*}$ & 0.145 & 0.4486 \\
\hline GA (val/met) & 85 & 69.105 & 47 & 37.0 & $0.0001 *$ & 3.807 & $0.4748^{\dagger}$ \\
\hline $\mathrm{AA}(\mathrm{met} / \mathrm{met})$ & 30 & 24.390 & 30 & 23.6 & 0.9999 & 1.043 & $0.0206^{\dagger}$ \\
\hline $\mathrm{GA}+\mathrm{AA}$ & 115 & 93.496 & 77 & 60.63 & $0.0001^{*}$ & 9.334 & $0.5339^{\dagger}$ \\
\hline G-allele (val) & 101 & 41.057 & 147 & 57.87 & $0.0001^{*}$ & 0.507 & 0.2835 \\
\hline A-allele (met) & 145 & 58.943 & 107 & 42.13 & $0.0001^{*}$ & 1.072 & $0.2834^{\dagger}$ \\
\hline
\end{tabular}

$\mathrm{N}=$ number of subjects; $\mathrm{RR}=$ relative risk; $\mathrm{EF}=$ etiological fraction; $\mathrm{PF}=$ preventive fraction. $*$ Statistically significant.

\begin{tabular}{|c|c|c|c|c|c|c|c|}
\hline \multirow[t]{2}{*}{ Genotype/ allele } & \multicolumn{2}{|c|}{ Patients $(\mathrm{N}=49)$} & \multicolumn{2}{|c|}{ Controls $(\mathrm{N}=50)$} & \multirow[t]{2}{*}{$\mathrm{P}$} & \multirow[t]{2}{*}{ RR } & \multirow[t]{2}{*}{$\mathrm{EF} * / \mathrm{PF}$} \\
\hline & $\mathrm{N}$ & $\%$ & $\mathrm{~N}$ & $\%$ & & & \\
\hline GG (val/val) & 4 & 8.163 & 4 & 8 & 0.999 & 1.0222 & $0.0108^{*}$ \\
\hline GA (val/met) & 26 & 53.061 & 24 & 48 & 0.689 & 1.2246 & $0.0953 *$ \\
\hline AA (met/met) & 19 & 38.775 & 22 & 44 & 0.684 & 0.806 & 0.1002 \\
\hline $\mathrm{GA}+\mathrm{AA}$ & 45 & 91.84 & 46 & 92 & 0.999 & 0.978 & 0.0109 \\
\hline G-allele (val) & 34 & 34.69 & 32 & 32 & 0.763 & 1.1289 & $0.0588^{*}$ \\
\hline A-allele (met) & 64 & 65.31 & 68 & 68 & 0.763 & 0.8858 & 0.0622 \\
\hline
\end{tabular}

$\mathrm{N}=$ number of subjects; $\mathrm{RR}=$ relative risk; $\mathrm{EF}=$ etiological fraction; $\mathrm{PF}=$ preventive fraction.

The effect of gender on genotype and allele frequencies of the Val ${ }^{158}$ Met polymorphism in Saudi schizophrenia patients and control subjects is presented in Tables 4 and 5. We observed a significant difference in the frequencies of the Val/Met genotype between male $(69.10 \%)$ and female $(53.06 \%)$ patients. However, on comparison with controls of the same gender, female patients did not show a significant difference $(\mathrm{P}=0.689)$ while male patients were found to have a very significant difference in the distribution of alleles as well as genotypes of the Val ${ }^{158}$ Met polymorphism $(\mathrm{P}=0.0001)$. Gender difference was very significant and male patients had significant association with the Val ${ }^{158}$ Met polymorphism, while female patients did not (Tables 4 and 5). The association of the Val ${ }^{158}$ Met polymorphism with schizophrenia in different populations worldwide reported by various authors are compared in Table 6 , which indicated quite conflicting results, and even the same populations such as Chinese, Caucasian and Japanese studied by different authors gave different results.

\section{DISCUSSION}

Our results of genotype and allele frequencies suggest that the COMT Val ${ }^{158} \mathrm{Met}$ polymorphism has a significant association with schizophrenia in Saudis. Our findings are in agreement with several earlier studies on Chinese (Wang et al., 2010; Wan et al., 2011), Indian (Gupta et al., 2009), Malays (Wan et al., 2011), Japanese (Ohmori et al., 1998), and Israeli (Kotler et al., 1999) populations, which also observed a significant association between the Val ${ }^{158}$ Met genotype of the COMT polymorphism with schizophrenia. 


\begin{tabular}{|c|c|c|c|}
\hline Population/group studied & Genotype/Allele & $P$ values & References \\
\hline Saudis & $\mathrm{Val} / \mathrm{Met}$ & 0.0001 & Present study \\
\hline Saudis & Met & 0.0029 & Present study \\
\hline Caucasian & Val $>$ Met & 0.0015 & Kunugi et al., 1997 \\
\hline Caucasian and African-American & Val & 0.043 & Wonodi et al., 2006 \\
\hline Caucasian & No association & 0.37 & Karayiogou et al., 1998 \\
\hline Caucasian & No association & 0.20 & Rosa et al., 2004 \\
\hline Chinese & Val/Met & - & Wang et al., 2010 \\
\hline Chinese & Val/Met & - & Wan et al., 2011 \\
\hline Chinese & No association & 0.54 & Fan et al., 2005 \\
\hline Chinese & No association & - & Kong et al., 2011 \\
\hline Han Chinese & No association & - & Kang et al., $2010 \mathrm{a}$ \\
\hline Han Chinese & No association & - & Chen et al., 2011 \\
\hline Han Chinese & No association & 0.11 & Zhang et al., 2012 \\
\hline Malays & Val/Met & - & Wan et al., 2011 \\
\hline Indian & $\mathrm{Val} / \mathrm{Met}$ & - & Wan et al., 2011 \\
\hline Indian & $\mathrm{Val} / \mathrm{Met}$ & 0.044 & Gupta et al., 2009 \\
\hline Turks & Met/Met & 0.001 & Sazci et al., 2004 \\
\hline Israeli & Met & - & Kotler et al., 1999 \\
\hline Jewish (Israeli) & $\mathrm{Val} / \mathrm{Val}$ & 0.0074 & Shifman et al., 2002 \\
\hline Syrian & No association & - & Lajin et al., 2011 \\
\hline Japanese & Met & 0.028 & Ohmori et al., 1998 \\
\hline Japanese & No association & - & Okochi et al., 2009 \\
\hline Spanish & $\mathrm{Val} / \mathrm{Met}^{*}$ & 0.04 & Lafuente et al., 2008 \\
\hline Spanish & Val/Met* & 0.03 & Hoenicka et al., 2010 \\
\hline Spanish & Val/Met* & 0.023 & Costas et al., 2011 \\
\hline Australian & $\mathrm{Val} / \mathrm{Val}$ & - & Voisey et al., 2012 \\
\hline Polish & No association & - & Pawel et al., 2010 \\
\hline German & No association & - & Nieratschker et al., 2010 \\
\hline Korean & No association & - & Kang et al., 2010b \\
\hline
\end{tabular}

*Protective for schizophrenia.

On the other hand, a number of investigators have reported a lack of association between the Val ${ }^{158}$ Met genotype and schizophrenia in African-American (Wonodi et al., 2006), Chinese (Kang et al., 2010a; Chen et al., 2011; Kong et al., 2011), Caucasian (Rosa et al., 2004), Japanese (Okochi et al., 2009), Polish (Paweł et al., 2010), Korean (Kang et al., 2010b), and German (Nieratschker et al., 2010) populations.

In this study, we observed a highly significant association between the Met-COMT allele in Saudi patients with schizophrenia (Table 1). Our finding is in agreement with earlier reports by Ohmori et al. (1998), in Japanese, and Kotler et al. (1999), in Israeli population. The Met-COMT allele has also been reported to be associated with violent/aggressive behavior in schizophrenia (Tosato et al., 2011). Earlier, an association has been reported between the lowactivity Met allele with fewer perseverative errors in the Wisconsin Card Sorting Test (WCST) and a more efficient task-related pattern of activation in the prefrontal cortex (PFC) in the control subjects as compared to schizophrenia patients. On the other hand, some other reports have suggested a significant association between the Val-COMT allele and susceptibility to schizophrenia (Shifman et al., 2002; Wonodi et al., 2006; Hoenicka et al., 2010; Voisey et al., 2010). Wonodi et al. (2006) estimated that the Val-COMT allele accounts for up to $23 \%$ of the burden of schizophrenia. It has been suggested that the Val-COMT allele is associated with poorer performances, compared to the Met-COMT allele, in cognitive tasks of prefrontal function. The underlying mechanism of such behavioral differences has been related to lower prefrontal dopamine levels arising from higher dopamine catabolism mediated by the Val-COMT allele (Chen et al., 2004). 
Overall, the analysis of available data clearly shows inconsistent finding even in various inter- and intra-ethnic groups (Table 6) with no clear-cut evidence of positive or negative association between the COMT Val ${ }^{158}$ Met polymorphism and schizophrenia (Fan et al., 2005; Kang et al., 2010a,b). According to some investigators, this ambiguity in results may be attributed to functional state of disease such as violent/aggressive behavior (Kotler et al., 1999; Tosato et al., 2011), positive/negative symptoms (Wang et al., 2010; Li et al., 2012), age of onset, cognitive function, and severity of psychotic symptoms (Sagud et al., 2010).

In this study, we segregated schizophrenia patients according to their negative (91 patients) and positive symptoms (81 patients) based on criteria described by Kay et al. (1987). Although both groups of patients with negative and positive symptoms had similar significant association with the Val ${ }^{158}$ Met COMT polymorphism, there was no significant difference between the genotype frequencies between these two groups. Our finding is in agreement with Strous et al. (2006) who suggested that COMT genotypes are not related to the clinical symptomatology of schizophrenia. A potential explanation for this lack of association between $\mathrm{Val}^{158} \mathrm{Met}$ COMT polymorphism with either negative or positive symptoms has been attributed to the fact that some other modifying genes may be involved, which may be responsible for the manifestation of positive and negative symptoms in the clinical expression of schizophrenia. Thus, the effect of COMT on various symptom expressions may not necessarily be generalized. Further studies are certainly mandated to investigate the relationship in a large patient cohort to investigate various unproven hypotheses.

The effect of gender on genotype and allele frequencies of the $\mathrm{Val}{ }^{158} \mathrm{Met}$ polymorphism in Saudi schizophrenia patients and control subjects was very clear. We observed a significant difference in the frequencies of the Val/Met genotype between male and female patients. However, on comparison with controls of the same gender, female patients had no association while male patients were found to have a very significant association with the $\mathrm{Val}^{158} \mathrm{Met}$ polymorphism $(\mathrm{P}=0.0001)$. Our findings are in agreement with earlier studies that observed an effect of gender on the COMT Val ${ }^{158}$ Met polymorphism (Kempton et al., 2009). Gender-specific genetic component in schizophrenia has been suggested by Shifman et al. (2002). Contrary to these findings, a twin study failed to find evidence of specific gender effects for schizophrenia, perhaps reflecting the low statistical power of that approach (Shifman et al., 2002). The gender-specific phenotypic differences observed in patients with schizophrenia may reflect the distinction between males and females in the etiology of schizophrenia due to difference in COMT activity. It has been observed that females have $20-30 \%$ lower COMT activity as compared to males perhaps due to down regulation of COMT by estrogen in females (Coman et al., 2010). Hence, the Val ${ }^{158} \mathrm{Met}$ polymorphism may be mediated by gender. At present, there is very limited data to elucidate the multifaceted interplay between the COMT polymorphism and gender. Further studies are warranted to determine the role of gender in the COMT polymorphism in schizophrenia and other dopamine-regulated disorders.

In summary, this study provides evidence for an association between the COMT Val ${ }^{158}$ Met polymorphism and schizophrenia in the Saudi population. Our data further suggest that gender exerts a significant effect on the frequency distribution of genotypes and alleles of the COMT Val ${ }^{158}$ Met polymorphism while disease manifestation such as positive or negative symptoms has no significant impact on it. 


\section{ACKNOWLEDGMENTS}

The authors thank S. Sadaf Rizvi for her help with laboratory work.

\section{REFERENCES}

Andreasen NC and Olsen S (1982). Negative v positive schizophrenia. Definition and validation. Arch. Gen. Psychiatry 39: 789-794.

Chen CY, Lu RB, Yeh YW, Shih MC, et al. (2011). Association study of catechol-O-methyltransferase gene polymorphisms with schizophrenia and psychopathological symptoms in Han Chinese. Genes Brain Behav. 10: 316-324.

Chen X, Wang X, O'Neill AF, Walsh D, et al. (2004). Variants in the catechol-o-methyltransferase (COMT) gene are associated with schizophrenia in Irish high-density families. Mol. Psychiatry 9: 962-967.

Coman IL, Gnirke MH, Middleton FA, Antshel KM, et al. (2010). The effects of gender and catechol O-methyltransferase (COMT) Val108/158Met polymorphism on emotion regulation in velo-cardio-facial syndrome (22q11.2 deletion syndrome): An fMRI study. Neuroimage 53: 1043-1050.

Costas J, Sanjuán J, Ramos-Ríos R, Paz E, et al. (2011). Heterozygosity at catechol-O-methyltransferase Val158Met and schizophrenia: new data and meta-analysis. J. Psychiatr. Res. 45: 7-14.

Fan JB, Zhang CS, Gu NF, Li XW, et al. (2005). Catechol-O-methyltransferase gene Val/Met functional polymorphism and risk of schizophrenia: a large-scale association study plus meta-analysis. Biol. Psychiatry 57: 139-144.

Gupta M, Bhatnagar P, Grover S, Kaur H, et al. (2009). Association studies of catechol-O-methyltransferase (COMT) gene with schizophrenia and response to antipsychotic treatment. Pharmacogenomics 10: 385-397.

Harrison PJ and Weinberger DR (2005). Schizophrenia genes, gene expression, and neuropathology: on the matter of their convergence. Mol. Psychiatry 10: 40-68.

Hoenicka J, Garrido E, Martinez I, Ponce G, et al. (2010). Gender-specific COMT Val158Met polymorphism association in Spanish schizophrenic patients. Am. J. Med. Genet. B Neuropsychiatr. Genet. 153B: 79-85.

Howes OD, Montgomery AJ, Asselin MC, Murray RM, et al. (2009). Elevated striatal dopamine function linked to prodromal signs of schizophrenia. Arch. Gen. Psychiatry 66: 13-20.

Johnstone EC, Ebmeier KP, Miller P, Owens DG, et al. (2005). Predicting schizophrenia: findings from the Edinburgh High-Risk Study. Br. J. Psychiatry 186: 18-25.

Kang C, Xu X, Liu H and Yang J (2010a). Association study of catechol-O-methyltransferase (COMT) gene Val158Met polymorphism with auditory P300 in Chinese Han patients with schizophrenia. Psychiatry Res. 180: 153-155.

Kang HJ, Choe BM, Kim SH, Son SR, et al. (2010b). No association between functional polymorphisms in COMT and MTHFR and schizophrenia risk in Korean population. Epidemiol. Health 32: e2010011.

Karayiorgou M, Gogos JA, Galke BL, Wolyniec PS, et al. (1998). Identification of sequence variants and analysis of the role of the catechol-O-methyl-transferase gene in schizophrenia susceptibility. Biol. Psychiatry 43: 425-431.

Kay SR, Fiszbein A and Opler LA (1987). The positive and negative syndrome scale (PANSS) for schizophrenia. Schizophr. Bull. 13: 261-276.

Kempton MJ, Haldane M, Jogia J, Christodoulou T, et al. (2009). The effects of gender and COMT Val158Met polymorphism on fearful facial affect recognition: a fMRI study. Int. J. Neuropsychopharmacol. 12: 371-381.

Kong FZ, Peng ZZ, Jiang TY and Hong XH (2011). An association study of COMT gene polymorphisms with schizophrenia. Zhonghua Yi Xue Yi Chuan Xue Za Zhi 28: 208-211.

Kotler M, Barak P, Cohen H, Averbuch IE, et al. (1999). Homicidal behavior in schizophrenia associated with a genetic polymorphism determining low catechol O-methyltransferase (COMT) activity. Am. J. Med. Genet. 88: 628-633.

Kunugi H, Vallada HP, Sham PC, Hoda F, et al. (1997). Catechol-O-methyltransferase polymorphisms and schizophrenia: a transmission disequilibrium study in multiply affected families. Psychiatr. Genet. 7: 97-101.

Lafuente A, Bernardo M, Mas S, Crescenti A, et al. (2008). Polymorphism of dopamine D2 receptor (TaqIA, TaqIB, and $-141 \mathrm{C} \mathrm{Ins/Del)} \mathrm{and} \mathrm{dopamine} \mathrm{degradation} \mathrm{enzyme} \mathrm{(COMT} \mathrm{G158A,} \mathrm{A-278G)} \mathrm{genes} \mathrm{and} \mathrm{extrapyramidal} \mathrm{symptoms}$ in patients with schizophrenia and bipolar disorders. Psychiatry Res. 161: 131-141.

Lajin B, Alachkar A, Hamzeh AR, Michati R, et al. (2011). No association between Val158Met of the COMT gene and susceptibility of schizophrenia in the Syrian population. N. Am. J. Med. Sci. 3: 176-178.

Li WJ, Kou CG, Yu Y, Sun S, et al. (2012). Association of catechol-O-methyltransferase gene polymorphisms with schizophrenia and negative symptoms in a Chinese population. Am. J. Med. Genet. B Neuropsychiatr. Genet. 159B: 370-375.

Lotta T, Vidgren J, Tilgmann C, Ulmanen I, et al. (1995). Kinetics of human soluble and membrane-bound catechol O-methyltransferase: a revised mechanism and description of the thermolabile variant of the enzyme. Biochemistry 34: 4202-4210. 
Murphy KC (2002). Schizophrenia and velo-cardio-facial syndrome. Lancet 359: 426-430.

Nieratschker V, Frank J, Muhleisen TW, Strohmaier J, et al. (2010). The catechol-O-methyl transferase (COMT) gene and its potential association with schizophrenia: findings from a large German case-control and family-based sample. Schizophr. Res. 122: 24-30.

Ohmori O, Shinkai T, Kojima H, Terao T, et al. (1998). Association study of a functional catechol-O-methyltransferase gene polymorphism in Japanese schizophrenics. Neurosci. Lett. 243: 109-112.

Okochi T, Ikeda M, Kishi T, Kawashima K, et al. (2009). Meta-analysis of association between genetic variants in COMT and schizophrenia: an update. Schizophr. Res. 110: 140-148.

Paweł K, Hauser J, Skibińska M, Szczepankiewicz A, et al. (2010). Family based association study of DRD1, DRD2, DRD3, DRD4, DAT, COMT gene polymorphism in schizophrenia. Psychiatr. Pol. 44: 405-413.

Rosa A, Peralta V, Cuesta MJ, Zarzuela A, et al. (2004). New evidence of association between COMT gene and prefrontal neurocognitive function in healthy individuals from sibling pairs discordant for psychosis. Am. J. Psychiatry 161: 1110-1112.

Ruiz-Sanz JI, Aurrekoetxea I, Ruiz del AA and Ruiz-Larrea MB (2007). Detection of catechol-O-methyltransferase Val158Met polymorphism by a simple one-step tetra-primer amplification refractory mutation system-PCR. Mol. Cell Probes 21: 202-207.

Sagud M, Mück-Seler D, Mihaljević-Peles A, Vuksan-Cusa B, et al. (2010). Catechol-O-methyl transferase and schizophrenia. Psychiatr. Danub. 22: 270-274.

Sazci A, Ergul E, Kucukali I, Kilic G, et al. (2004). Catechol-O-methyltransferase gene Val108/158Met polymorphism, and susceptibility to schizophrenia: association is more significant in women. Brain Res. Mol. Brain Res. 132: 51-56.

Schallreuter KU, Levenig C, Kühnl P, Löliger C, et al. (1993). Histocompatability antigens in vitiligo: Hamburg study on 102 patients from Northern Germany. Dermatology 187: 186-192.

Shifman S, Bronstein M, Sternfeld M, Pisanté-Shalom A, et al. (2002). A highly significant association between a COMT haplotype and schizophrenia. Am. J. Hum. Genet. 71: 1296-1302.

Strous RD, Lapidus R, Viglin D, Kotler M, et al. (2006). Analysis of an association between the COMT polymorphism and clinical symptomatology in schizophrenia. Neurosci. Lett. 393: 170-173.

Tosato S, Bonetto C, Di Forti M, Collier D, et al. (2011). Effect of COMT genotype on aggressive behaviour in a community cohort of schizophrenic patients. Neurosci. Lett. 495: 17-21.

Voisey J, Swagell CD, Hughes IP, Lawford BR, et al. (2012). HapMap tag-SNP analysis confirms a role for COMT in schizophrenia risk and reveals a novel association. Eur. Psychiatry 27: 372-376.

Wan CL, Zainal NZ, Lian LH and Mohamed Z (2011). Association of the functional polymorphism in the catechol-Omethyltransferase gene with schizophrenia in the three ethnic groups of the Malaysian population. Psychiatry Res. 189: 67-71.

Wang Y, Fang Y, Shen Y and Xu Q (2010). Analysis of association between the catechol-O-methyltransferase (COMT) gene and negative symptoms in chronic schizophrenia. Psychiatry Res. 179: 147-150.

Wonodi I, Mitchell BD, Stine OC, Hong LE, et al. (2006). Lack of association between COMT gene and deficit/nondeficit schizophrenia. Behav. Brain Funct. 2: 42.

Zhang F, Liu C, Chen Y, Wang L, et al. (2012). No association of catechol-O-methyltransferase polymorphisms with schizophrenia in the Han Chinese population. Genet. Test. Mol. Biomarkers 16: 1138-1141. 